University for Business and Technology in Kosovo

UBT Knowledge Center

UBT International Conference

2012 UBT International Conference

Nov 2nd, 9:00 AM - Nov 3rd, 5:00 PM

\title{
The Creative Process of Architecture and Building Information Modeling
}

Daniel Guralumi

Albanian University, d.guralumi@albanianuniversity.edu.al

Follow this and additional works at: https://knowledgecenter.ubt-uni.net/conference

Part of the Architecture Commons

\section{Recommended Citation}

Guralumi, Daniel, "The Creative Process of Architecture and Building Information Modeling" (2012). UBT International Conference. 9.

https://knowledgecenter.ubt-uni.net/conference/2012/all-events/9

This Event is brought to you for free and open access by the Publication and Journals at UBT Knowledge Center. It has been accepted for inclusion in UBT International Conference by an authorized administrator of UBT Knowledge Center. For more information, please contact knowledge.center@ubt-uni.net. 


\title{
THE CREATIVE PROCESS OF ARCHITECTURE AND THE BUILDING INFORMATION MODELING
}

\author{
Phd. Daniel Guralumi ${ }^{1}$ \\ ${ }^{1}$ Albanian University, Tirana,Faculty of Architecture and Engineers,Department of Architecture \\ d.guralumi@albanianuniversity.edu.al
}

\begin{abstract}
Building Information Modeling and architecture, more commonly known as BIM is the subject of many discussions in the architectural communities lately. The architectural design is a complex set of transactions where the knowledge of many disciplines meets the professionalism of people involved, however most of the interaction is done on paper-based communication. Building Information Modeling, the subject of this paper, is a design strategy which aspires to be much more than a mere information exchange tool: it is rather a coordinated and holistic approach aimed to assist designer, engineers, developers, decision makers, contractors and owners. A digital model derived from B.I.M. (acronym for Building Information Modeling) software allows, among other features, the integration of the necessary data to all the participants of the project. It maintains and shares up to date information, facilitates the changes of the building components in real time and describes the project in a coherent way. Aggregating the information is the very essence of B.I.M., where sorting and the semantics of the building components are combined into a multidisciplinary interactive archive. The NIBS (National Institute of Building Science) defines B.I.M as "a representation of digital physical characteristics and functional properties of an object". At the same time B.I.M serves to share resources and information that will accompany the object in its project life cycle. The aim of this paper is to clear some concepts that are often ambiguous and confusing.
\end{abstract}

Keywords: graphical representation, parametric building model, continuous updating of data, productivity, $3 D$ modeling for building construction

\section{Introduction}

The process of design in architecture is a set of fragmented operations dependent on communication systems still largely based on paper documents. Errors and omissions resulting from failure to update or compilation deviations, are often the cause of delays and unexpected costs. The ambitious paradigm design B.I.M. could instead achieve a complete integration between different disciplines. One of the most common problems associated with paper based communication is the considerable amount of time and money spent on decision-making, to generate documents, the cost estimates, the analysis of the energy input, the structural analysis and other related procedures involved in the process.

The B.I.M. approach on the contrary implies a continuous update in real time between the elements of the project and is intended to replace traditional C.A.D. (Computer Aided Design) as a means of processing for the construction of an integrated model, unique by definition and usable by all operating figures for each stage of the process. B.I.M. approach limits the loss of content in information dataset from one step to another, qualifying as a tool of choice to realize any subsequent modification. The tools have changed the way we think, we develop and we present various types of data, in the construction industry a sector characterized by a considerable innovation and change. The evolution from C.A.D., electronic drawing board to modeling B.I.M, has made possible the transition from traditional plan views of the building (Orthographic projections) to the virtual simulations, full of information directly correlated to documents that define and specify the production methods. (cambio diapositiva)

Nevertheless, the practice wants a graphic containing views of 3D models produced with the most different software, realize the most part only the geometric description.

The method of levels to organize graphical information 2D or 3D does not imply the consciousness of objects represented. The information useful to an architectural project are not only graphic or geometric, but also annotative. Using standard management that takes advantage of this sort makes effective the digital technology.

It's clear that this approach is still far from B.I.M., where the interpretation of the building is presented as a unique integrated database components not only described by their geometry but that serve as graphical index for its largest content entering in fact the B.I.M. technology in the mainstream of software systems that are identified in the scientific literature as the IPDB (Integrated Project Database). This is not to stop using C.A.A.D. 
C.A.A.D technology have known from their birth a rapidly developing that has grown exponentially their possible applications, from simple computer graphs for the two-dimensional drawing, to become powerful tools for structuring the project in three dimensions. The C.A.A.D. has changed the conception of graphical representation, allowing the use of specific procedures own the automatic design, custom for architectural and prodromal approach to information hierarchy typical of B.I.M

The transition from the traditional method exposed aided drawing of the generation of a model building, a faithful and complete of all the: the B.I.M. is before anything else a perfect master of digital techniques of organization data, a well aware of the importance to describe the building in all its components constituents.

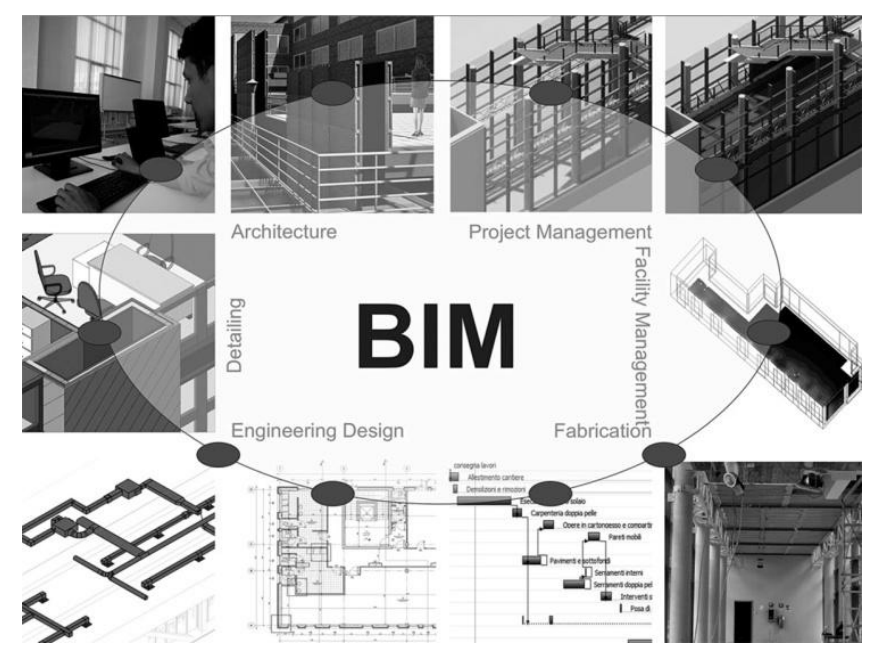

The B.I.M. therefore, is a set of activities, coordinates one or more digital models structured as a "parametric building model, parametric building model, capable of automatically propagating the effects of a change throughout the model and providing valuable feedback on the implications of that change on the space, the building systems, the products selected, and the construction cost.

In addition to parametric building model, CAD systems must provide facile tools for instantly presenting this information in the multiple representations necessary for communication, collaboration and commerce. Since from the stage of the concept it is much more easy to imagine the spaces and functions through schemes or planimetric views easier to manage and leaving in the second instance to the modeler B.I.M. the responsibility to check for interference or criticality of the elements in their size up. 


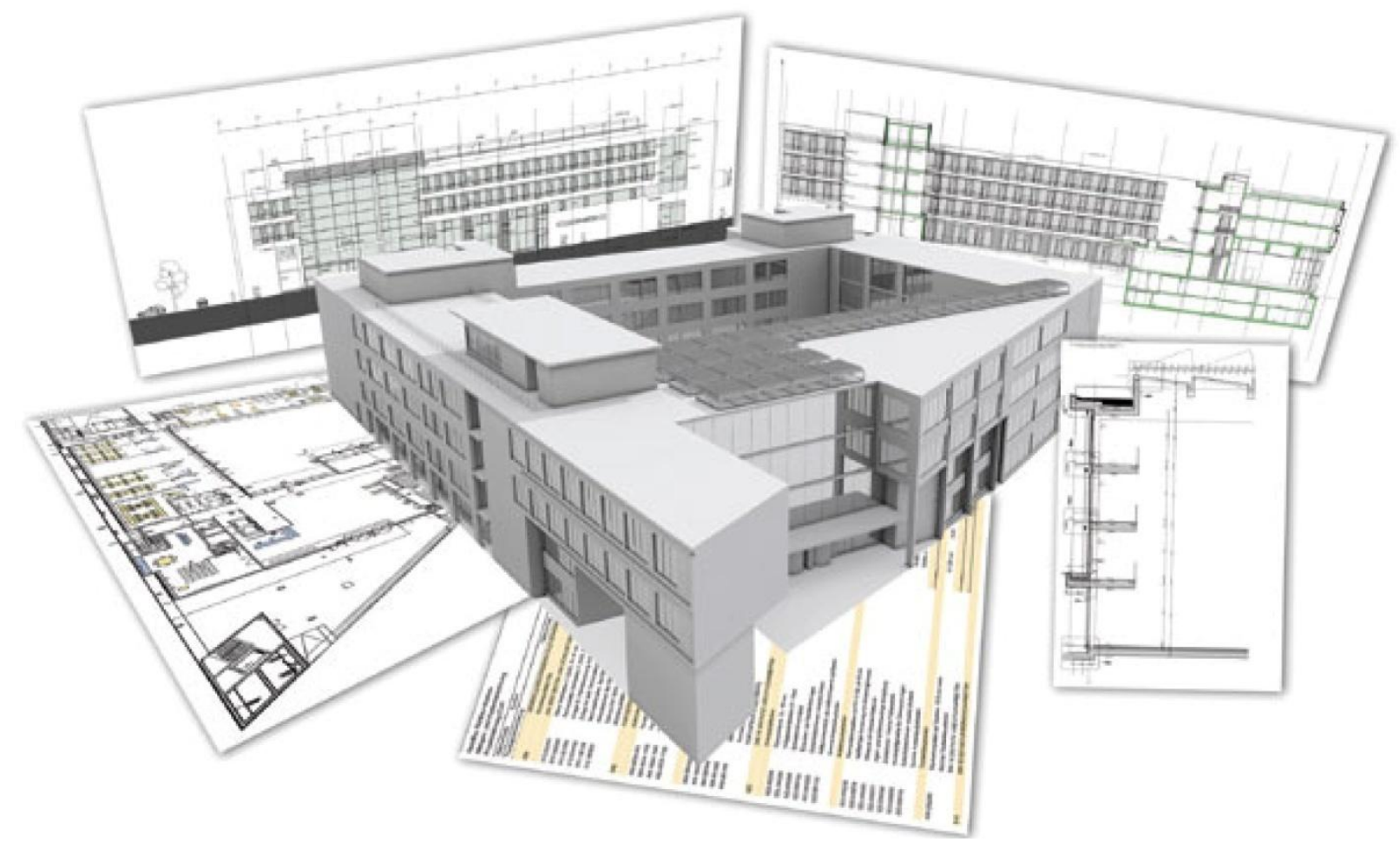

A BIM in fact, is organized to design buildings through the use of objects defined intelligent, able to establish relationships with other members the model: the elements introduced are three-dimensional graphical objects able to relate to each other in a logical aggregation / assembly, are instead of a specific representation of the technological component which they identify.

In this way a window, for example, will not be a simple Boolean Wall subtraction performed on the object to generate a hole, but it alone will be an parametric element with specific characteristics and belonging to a specific context, able to properly coordinate the wall.

The relative facility of introducing changes to the intelligent elements, governed by parameters that define constraints and behaviors, then opens the way to a richer more versatile in architecture, consisting of the opportunity to introduce and evaluate solutions alternatives.

The architectural project, where all actors participations with their specializations, requires extensive consultation between the figures, so if the update information is slow and expensive, often are prepared only some project ideas, discarding other due to lack of resources.

Modifications and variants may be introduced in a BIM actors in participation at different times of the design flow, while maintaining consistency and coordination in the data.

At the end of the introduction of the constituent elements, the digital model updated and complete in its detail allows production in an automatic way of a wide range of papers, including views more or less realistic views of architectural tables listed in levels of detail dependent on the scale of representation, schedules, schedules of quantities and materials, analytical cards of components, timelines and so on.

\subsection{B.I.M SOFTWARE CHANGE THE WAY OF ARCHITETURE DESIGN}

BIM is becoming increasingly in the context of architectural design. At the global level, according to a recent study by the McGraw-Hill Construction the transition to BIM is essentially dictated by the following factors:

ability to improve significantly the communication between the designers,

parametric modifications of objects,

possibility of reducing the costs of construction.

In the design with tools "not BIM "the greatest economic loss attributable to the need to redesign partially or totally the project, followed by lost time to identify the latest version of the drawings and the purchase of any software that allows to communicate with other software 


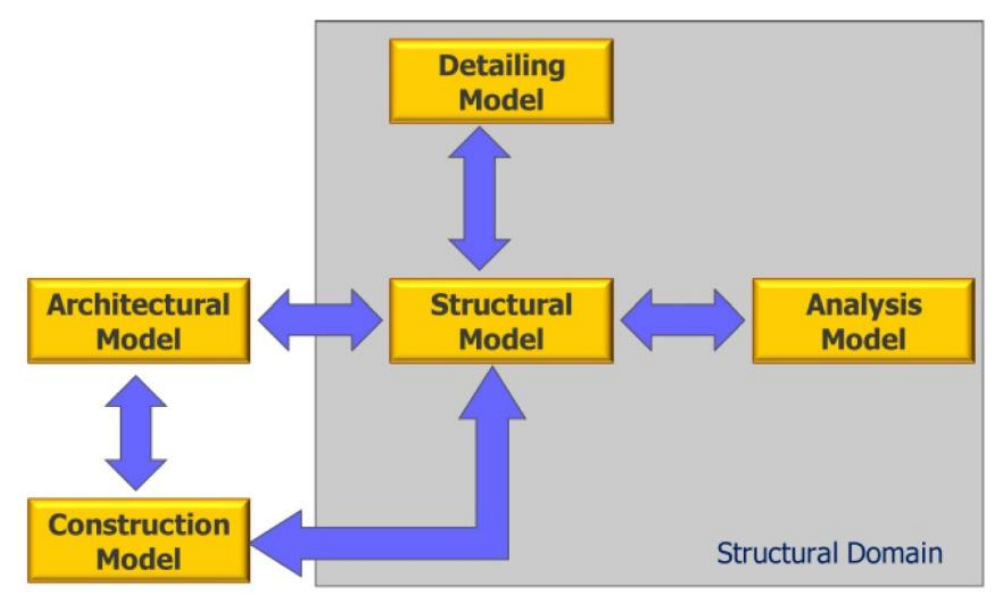

The introduction of software B.I.M. is becoming more and more widely offer commercial producers. Starting the historical product AutoCAD, has established itself in the market through the acquisition of companies connected to the world of computer graphics. Autodesk has acquired Revit Technologies Inc., a manufacturer of Revit, a program for operating systems Windows added to online marketing as parametric design tool to B.I.M. Through the parametric inserted into the native technology, Revit provides for the immediate conceptualization threedimensional shapes and their subsequent development, serving as the natural candidate for substitution of AutoCAD.
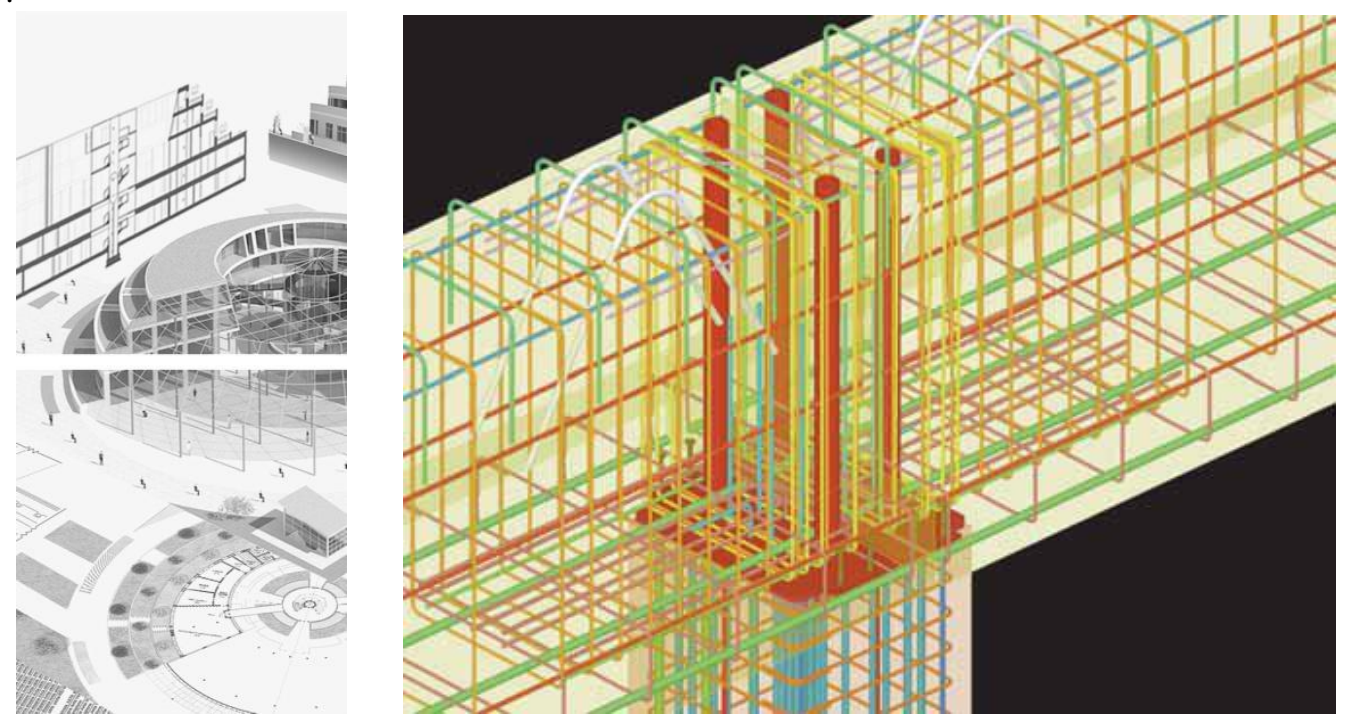

Revit therefore prepares to become the de facto successor to the industry standard for the design, with three specific versions for different disciplines use:

Revit Architecture, for architects and designers building (formerly Revit Building);

Revit Structure, for structural engineers, borrowed in Robot Structures,

Revit MEP (Mechanical, Electrical, and Plumbing) for mechanical, electrical.

These software retrace in parallel the characteristics that the approach to the Building Information Modeling must support -

Unique description and overall project within a digital model;

- Management of "smart objects" as components of the model;

- Tracking of the model starting from a working environment $2 \mathrm{D}$ dimensional ready for 3D visualization of its components;

- Easy to edit parametric features of the elements;

- Possibility to study alternative solutions;

- Integration of the different disciplines by an archive coherent able to be exchanged without substantial lo ss of information;

- Continuous updating of data in cascade in different documents can be processed;

- Possibility of team-working with contemporary work on the same bas is of data;

- Output management by project printing of the drawings, calculation of, relationships, etc ... and the display architectural rendering. 
The Allplan software today verticalizes on B.I.M. the technologies of software houses: for Allplan, as for Revit, there are different versions, depending on the end user and the requested content:

- Allplan Architecture, software package for architects, ranging from modeling sketch up for 3D animation;

- Allplan Engineering solution for engineering civil and structural engineering;

- Allplan systems, design solution technology services buildings;

- Allplan Precast dedicated to companies producing prefabricated components, especially in wood.

At the end of software dedicated to BIM parametric, we can mention Digital Project, a complex CAD system derived from Catia V5 of Dassault SYSTEMS that is developed by Gehry Technologies, startup company planning resulted entrepreneurship architect American architect Frank Owen Gehry.

All the buildings in fact, must fulfill a variety of functions, the obligation to meet basic needs such as structural strength, sustainability the installation choices for health internal, disposal and distribution of water, saving energy and so on.

Digital Project integrates all modules project trying to promote the exchange of information through a model starting that fundamentally respects these three points:

- The attributes and relations between objects assigned from the stage of architectural modeling can be interpreted in some by way analysis algorithms, then can abstract the complex geometries elements more simple and easy to handle;

The abstraction of geometric limits loss of consistency (in this case the physical model is clearly different in behavior even though geometrically homologous to the analytical);

- Levels of abstraction and their relationships with the real model are supported by all instruments used, or you can simulate effectively on model behavior element studied system.

The current version of Digital Project has been arranged to implement mode native IFC, further described in re gard to the high level of interoperability that it implies.

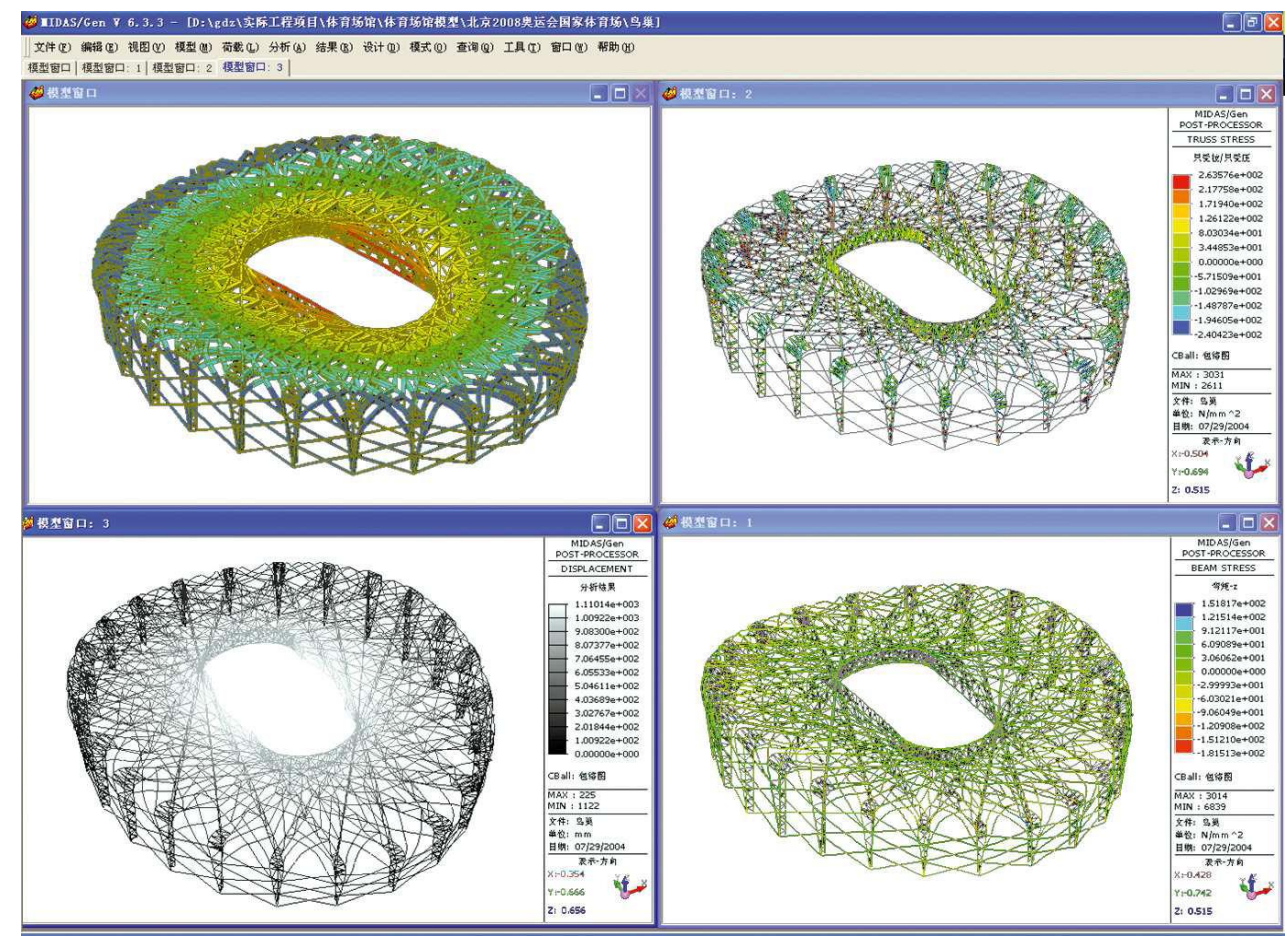

\section{CONCLUSIONS}

The B.I.M. want to define the process, in which a project can be fully described in high-level integration of knowledge.

Introduce new methodologies for the development of construction industry

The method BIM produce competitive costs and various different design solutions that allow an accurate assessment of the incidence of costs of the building project.

The BIM does what it promises: increased productivity, reduced errors in the design, documentation and coordination.

Allows the dialogue between the various specialized figures involved in the project. 
Offer and present to the client a final product of high quality.

\section{References}

Mingucci, R., 2008, La comunicazione del progetto nell'era digitale, in DISEGNARE CON Vol. 1. Bologna

Osello A.,2012, The future of drawing with BIM for Engineers and Architects, Dario Flaccovio Editore, Torino

Kymmel, W. , 2008, Building information modeling - Planning and managing construction projects with $4 d$ CAD

and simulations, McGraw Hill

http://www.ilgiornaledellarchitettura.com/art icoli/201 1/1/106111.html

http://www.corenet.gov.sg/

http://www.statsbygg.no/

http://www.gsa.gov/portal/content/105075

http://www.gsa.gov/graphics/pbs/Statement_of_Intention_to_support_Open_Standards_2011.pdf

http://www.deaca.dk/home/0/2

http://www.ebst.dk/file/9498/Revie woftheDevelop mentandImple mentationofIFCco mpatib le BIM.pdf

http://www.harpaceas.it/sito/prodotti.nsf/PagOK/MIDASGen

http://www.harpaceas.it/sito/prodotti.nsf/PagOK/Tekla_Structures

http://www.harpaceas.it/TS-Midas/tekla_midas_v8_flash.html

Garagnani , S. , 2010, Unpacking the "Chinese Box": Managing Knowledge in architectural digital models, in

ICERI Proceedings ( International Conference of Education, Research and Innovation), Madrid

Davis, P., 2010, Introducing Autodesk Revit Architecture 2011, Wiley Publishing Inc., Indianapolis, Indiana 